\title{
Clomid Plus Gonadotropin Versus Letrozole Plus Gonadotropin in Stimulation of Infertile Women
}

\author{
SarabKhlalaf Al-Juboory ${ }^{1}$, Mufeda AliJwad ${ }^{2}$, Muayad Sraibet Abood ${ }^{3}$ \\ ${ }^{1}$ M. B. Ch. B. HD Ob \& Gyn, Kirkuk Health Directorate, Kirkuk, Iraq, ${ }^{2}$ Lecturer Dr., Clinical Infertility, ${ }^{3}$ Assistant \\ Prof., Pharmacology, Al-Nahrain University, High Institute of Infertility Diagnosis and Assisted Reproductive \\ Technologies Baghdad, Iraq
}

\begin{abstract}
A comparative prospective study was conducted in the High Institute of Infertility Diagnosis and Assisted Reproductive Technologies/Al-Nahrain University, from September 2019 to March 2020. The study included 60 women who attended the infertility clinic of the High Institute of Infertility Diagnosis and Assisted Reproductive Technologies/Al-Nahrain University. Follitropin Alfa ampoules 75 IU, subcutaneous, from 7th day of menstrual cycle and the dose was adapted according to the ovarian response to the dose of treatment. Other twenty females were treated with Femara (Letrozole). The study showed that the highest mean of LH (in the day of triggering of the follicle) was recorded in women under Clomid +FSH treatment $(13.52 \pm 7.22 \mathrm{mlU} / \mathrm{ml})$ followed the control group $(10.1 \pm 4.21 \mathrm{mlU} / \mathrm{ml})$ and the lowest mean was in women received Letrozole+ FSH $(8.67 \pm 4.54 \mathrm{mlU} / \mathrm{ml})$. The study also demonstrated that the mean of E2 was elevated significantly in women under Clomid + FSH treatment $(280.5 \pm 191.4 \mathrm{pg} / \mathrm{ml})$ followed by in women received Letrozole+ FSH $(214.2 \pm 141.4 \mathrm{pg} / \mathrm{ml})$ and the lowest mean was in the control group $(164.7 \pm 102.7 \mathrm{pg} / \mathrm{ml})$. The maximum mean of progesterone was recorded in in women under Clomid $+\mathrm{FSH}$ treatment $(4.15 \pm 3.2$ $\mathrm{ng} / \mathrm{ml}$ ) followed by women received Letrozole $+\mathrm{FSH}$ and the control group.
\end{abstract}

Keywords: Clomid; Female infertility; Letrozole; FSH.

\section{Introduction}

Infertility is a disease of the reproductive system, It can be defined by the failure to achieve a pregnancy after at least one year of regular unprotected sexual intercourse in women $<35$ years not using contraception and after six months in women $>35$ years or due to an impairment of a person's capacity to reproduce, either as an individual or with his/her partner, it affects about $10-15 \%$ of couples ${ }^{(1,2)}$. According to the World Health Organization (WHO) definition, a couple is considered infertile if, after 2 years of regular sexual intercourse, without contraception, the woman has not become pregnant ${ }^{(3)}$. Infertility is classified as primary (no pregnancy in the past) or secondary (pregnancy has occurred in the past not necessarily leading to live birth $)^{(4)}$. The causes of infertility can be generally classified into four groups: male, female, combined(both male and female) and unexplained .Some additional factors that may contribute to female infertility are behavioural factors such as diet, exercise, smoking, alcohol and drug use ${ }^{(5)}$. Combined infertility arises from the combination of male and female causes and it may be that each partner is independently fertile but the couple cannot conceive together without assistance. Nowadays, progress in ART has enabled the clinicians to treat many types of infertility ${ }^{(1)}$.

Endometrial receptivity is defined as a temporary unique sequence of factors that make the endometrium receptive to the implantation of the embryo ${ }^{(2)}$. It is the window of time when the uterine environment is conductive to blastocyst acceptance and subsequent implantation $^{(6)}$. The process of implantation may be separated into a series of developmental phases starting with the hatching of the blastocyst and attachment to the endometrium and sustained the formation of the placenta. The steps start with apposition, and progress through adhesion, penetration and invasion ${ }^{(7,8)}$. The aim of the study was to evaluate the use of clomid plus gonadotropin versus letrozole plus gonadotropinin stimulation of infertile women 


\section{Patients and Method}

A comparative prospective study was conducted in the High Institute of Infertility Diagnosis and Assisted Reproductive Technologies/Al-Nahrain University, from September 2019 to March 2020. The study included a total of 60 women who attended the infertility clinic of High Institute of Infertility Diagnosis and Assisted Reproductive Technologies/Al-Nahrain University from September 2019 to March 2020. All couples subjected to a full history taking, complete general examination, complete gynecological examination and infertility workup including: husband's seminal fluid analysis, basal hormonal analysis, uterine cavity assessment by ultrasound and tubal patency evaluation by hystrosalpingogram. The females were divided into two groups each consisting of 20 females. 20 females were stimulated with clomiphene citrate + gonadotropin and other 20 were stimulated by letrozole + gonadotropin. The ovarian stimulation protocol was chosen for each patient according to the following criteria age, history and hormonal assay. Evaluation of thickness and pattern of endometrium, size and number of mature follicles was performed by transvaginal ultrasonography in the 2nd day of menstrual cycle and cycle day 11-14 before HCG injection (ovulatory phase).Pregnancy outcome was used as a main comparative parameter between selected groups.

Ethical Approval: Written informed consent was given to every patient included in this study gave her written informed consent before taking part in the study, it was approved by the Ethics Committee and according to questionnaire forms designed.

History: The history was used to identify variables that affect the outcome of the ovarian induction program. The following variables were chosen for the initial analysis: age, type of infertility (primary or secondary), duration of infertility, menstrual history, any previous pregnancies, details about frequency of intercourse, use of vaginal douches after intercourse, and presence of any sexual dysfunction, chronic illnesses, surgery, and fertility investigations and or treatment. Etiology of infertility (unexplained infertility, male factor, minimal to mild endometriosis or ovarian dysfunction

Physical Examination: From external appearance of the patient obesity or low weight, acne or increased facial hair which may be a result of androgen excess. The thyroid gland was examined, abdominal examination for any surgical scars, mass and striae (Tkaczk-Włachetal.,
2016.). Gynecological examination was performed through vaginal examination to exclude any palpable pelvic mass or discomfort, normal vagina and cervix, the size, shape, position and mobility of the uterus was assessed.

Hormonal Analysis: In ART, correct diagnosis of the cause of infertility is a pre-requisite to successful treatment. Hormone tests are essential monitoring tools which were done in this study. In this study basal hormonal analysis was performed to all females included in the study on the $2^{\text {nd }}$ or $3^{\text {rd }}$ day of the menstrual cycle before starting control ovarian hyperstimulation $\mathrm{COH}$. These hormones include FSH, LH, Prolactin, E2, and progesterone. Blood samples were drawn from each patient $(5 \mathrm{ml})$ for hormonal assay, from median cubital vein by disposable syringe (Becton Dickinson company, USA), into a plain tube (AFCO, Jordon) allowed to clot for 30 minutes and centrifuged at $3500 \mathrm{rpm}$ within 10 minutes to separate the serum by using hormone analyzer.

Hysterosalpingography: Tubal patency and uterine cavity regularity were confirmed by hysterosalpingography, women with defective tubal patency or cavity deformity were excluded from the study.

Induction of Ovulation: Twenty females were treated by Clomiphene Citrate (CC) (Clomid, $50 \mathrm{mg}$ / tablets, Aventis Company, France) two times daily for five days from day two of menstrual cycle after basal transvaginal ultrasound to sixth day. Follitropin Alfa ampoules $75 \mathrm{IU}$, subcutaneous, from the 7 th day of menstrual cycle and the dose was adapted according to the ovarian response to the dose of treatment. Other twenty females were treated with Femara (Letrozole) [Novartis] Film-coated tablets contain $2.5 \mathrm{mg}$ Letrozole two times daily for 5 days from second day of menstrual cycle it is used to treat failed multiple cycles with ovulation induction by clomiphene citrate as used by other investigators. Follitropin Alfa ampoules 75 IU, subcutaneous, from the 7th day and the dose was adapted according to the ovarian response. Endometrial wash done at day of trigger for hyaluronic acid assessment.

\section{Results}

In this study, the majority of women enrolled in this study belonged to rural area and below 30 years, parity below 1 and infertile between 2-4 years, as shown in Table 1. 
Table 1: General characteristics of studied cases.

\begin{tabular}{|l|c|c|}
\hline Parameters & No. (Total: 40) & Percentage \\
\hline Residence & 24 & $60 \%$ \\
\hline Rural & 16 & $40 \%$ \\
\hline Urban & 22 & $55 \%$ \\
\hline Age groups (years) & 18 & $45 \%$ \\
\hline$<30$ & $29.5 \pm 4.52$ & \\
\hline$\geq 30$ & 21 & $52.5 \%$ \\
\hline Mean \pm SD & 10 & $25 \%$ \\
\hline Parity & 7 & 17.5 \\
\hline 0 & 2 & $5 \%$ \\
\hline 1 & $26.14 \pm 4.31$ & $10 \%$ \\
\hline $2-3$ & 13 & $57.5 \%$ \\
\hline $4-5$ & 4 & $32.5 \%$ \\
\hline Duration of infertility (years) & \\
\hline $2-4$ & 23 & \\
\hline $5-7$ & \multicolumn{2}{|c|}{} \\
\hline$>7$ & \multicolumn{2}{|c|}{} \\
\hline BMI & 21 & \\
\hline
\end{tabular}

The study showed that the highest mean of LH (in theday of triggering of the follicle) was recorded in women under Clomid +FSH treatment (13.52 \pm 7.22 $\mathrm{mlU} / \mathrm{ml})$ followed the control group $(10.1 \pm 4.21 \mathrm{mlU} / \mathrm{ml})$ and the lowest mean was in women received Letrozole + FSH $(8.67 \pm 4.54 \mathrm{mlU} / \mathrm{ml})$. The study also demonstrated that the mean of E2 was elevated significantly in women under Clomid +FSH treatment $(280.5 \pm 191.4$ $\mathrm{pg} / \mathrm{ml}$ ) followed by in women received Letrozole+ FSH $(214.2 \pm 141.4 \mathrm{pg} / \mathrm{ml})$ and the lowest mean was in the control group $(164.7 \pm 102.7 \mathrm{pg} / \mathrm{ml})$. The maximum mean of progesterone was recorded in in women under Clomid + FSH treatment $(4.15 \pm 3.2 \mathrm{ng} / \mathrm{ml})$ followed by women received Letrozole $+\mathrm{FSH}$ and the control group (Table 2).

Table 2: Levels of LH and E2 and progesterone among the study groups

\begin{tabular}{|c|c|c|c|}
\hline \multirow{2}{*}{$\begin{array}{l}\text { Mean } \pm \text { SD of hormones in day of } \\
\text { triggering of the follicle }\end{array}$} & \multicolumn{2}{|c|}{ Women under ovulation stimulation programs } & \multirow{2}{*}{$\frac{\text { P. value }}{(\text { Group A \& B })}$} \\
\hline & $\begin{array}{c}\text { Group A } \\
\text { (Received Letrozole +FSH) }\end{array}$ & $\begin{array}{c}\text { Group B } \\
\text { (Received Clomid }+ \text { FSH) }\end{array}$ & \\
\hline $\mathrm{LH}(\mathrm{mlU} / \mathrm{ml})$ & $8.67 \pm 4.54$ & $13.52 \pm 7.22$ & 0.001 \\
\hline $\mathrm{E} 2(\mathrm{pg} / \mathrm{ml})$ & $280.5 \pm 191.4$ & $214.2 \pm 141.4$ & 0.0001 \\
\hline Progesterone (ng/ml) & $4.15 \pm 3.2$ & $2.73 \pm 1.01$ & 0.001 \\
\hline
\end{tabular}

P. value ( $\leq 0.05$ : Significant) $(>0.05$ : Non-significant)

The study demonstrated that $55 \%$ of infertile women became pregnant one month after receiving letrozole + FSH and $50 \%$ of group B after receiving Clomid+FSH compared by $45 \%$ of the control group, although the result was non-significant (Table 3).

Table 3: Pregnancy rate in the studied groups

\begin{tabular}{|l|c|c|c|c|}
\hline \multirow{2}{*}{$\begin{array}{l}\text { Pregnancy after } \\
\text { stimulation }\end{array}$} & \multicolumn{2}{|c|}{\begin{tabular}{c} 
Women under ovulation stimulation programs \\
\cline { 2 - 5 }
\end{tabular}} & \multicolumn{2}{|c|}{$\begin{array}{c}\text { Group A } \\
\text { (Received Letrozole + FSH) }\end{array}$} \\
\cline { 2 - 5 } & No. & Received Clomid + FSH) & No. \\
\hline Positive & 11 & 55 & 10 & 50 \\
\hline Negative & 9 & 45 & 10 & 50 \\
\hline Total & $\mathbf{2 0}$ & $\mathbf{1 0 0}$ & $\mathbf{2 0}$ & $\mathbf{1 0 0}$ \\
\hline
\end{tabular}

$\mathrm{X}^{2}$ : 0.4 P. value: 0.81 (Non-significant) 
The study revealed that $36.36 \%$ of infertile women became with 2 follicles after receiving letrozole + FSH and $27.28 \%$ were with 3 follicles, while $50 \%$ of infertile women became with 2 follicles after receiving Clomid + FSH and 30\% were with 1 follicles (Table 4).

Table 4: Number of follicles in the studied groups

\begin{tabular}{|c|c|c|c|c|}
\hline \multirow{2}{*}{ No. of follicles } & \multicolumn{4}{|c|}{ Women under ovulation stimulation programs } \\
\cline { 2 - 5 } & Group A (Received Letrozole +FSH) & Group B (Received Clomid +FSH) \\
\cline { 2 - 5 } & No. & $\mathbf{\%}$ & No. & \% \\
\hline 1 & 2 & 18.18 & 3 & 30 \\
\hline 2 & 3 & 36.36 & 5 & 50 \\
\hline 3 & 4 & 27.28 & 2 & 20 \\
\hline 4 & 0 & 0 & 0 & 0 \\
\hline 5 & 2 & 18.18 & $\mathbf{1 0}$ & $\mathbf{1 0 0}$ \\
\hline Total & $\mathbf{1 1}$ & $\mathbf{1 0 0}$ & & 0 \\
\hline
\end{tabular}

$\mathrm{X}^{2}$ : 6.7 P. value: 0.31 (Non-significant)

Table 5: Level of hyaluronic acid in the studied groups

\begin{tabular}{|l|c|c|c|c|c|}
\hline \multirow{2}{*}{$\begin{array}{l}\text { Hyaluronic acid } \\
(\mathbf{p g} / \mathbf{m l})\end{array}$} & \multicolumn{2}{|c|}{ Women under ovulation stimulation programs } & \multicolumn{3}{|c|}{ P. value } \\
\cline { 2 - 6 } & $\begin{array}{c}\text { Group A } \\
\text { (Received Letrozole + FSH) }\end{array}$ & $\begin{array}{c}\text { Group B } \\
\text { (Received Clomid + FSH) }\end{array}$ & $\begin{array}{c}\text { (Group A } \\
\text { \& B) }\end{array}$ & $\begin{array}{c}\text { (Group A } \\
\text { \& Control) }\end{array}$ & $\begin{array}{c}\text { (Group B } \\
\text { \& Control) }\end{array}$ \\
\hline $\mathbf{N}$ & $\mathbf{2 0}$ & $\mathbf{2 0}$ & 0.09 & 0.031 & 0.029 \\
\hline$($ Mean \pm SD) & $158.7 \pm 19.7$ & $160.8 \pm 13.5$ & & \\
\hline
\end{tabular}

The study showed that mean ofhyaluronic acid was elevated significantly in women received letrozole plus FSH $(158.7 \pm 19.7 \mathrm{pg} / \mathrm{ml})$ followed by women received Clomid plus FSH $(160.8 \pm 13.5 \mathrm{pg} / \mathrm{ml})$.

\section{Discussion}

In this study, the majority of women enrolled in this study belonged to rural area and below 30 years, parity below 1 and infertile between 2-4 years. These findings were close to that reported by Ahmeid ${ }^{(7)}$, who found that the mean age of women under IVF was 30.36 year, his study also found that the mean of BMI was $25.9(\mathrm{~kg} /$ $\mathrm{m}^{2}$ ). Hameed and Ahmeid, ${ }^{(8)}$ in recent study included 45 women who enrolled in ART programs in infertility center for in-vitro fertilization (IVF) and found that the mean age of infertile women was $(31.80 \pm 5.38$ years $)$, his study also found that the mean of BMI was $25.36 \pm$ $1.99\left(\mathrm{~kg} / \mathrm{m}^{2}\right)$.Moreover Al-Dujaily et al ${ }^{(9)}$ found that the mean age of infertile women (31.0 year) and BMI 25.3 $(\mathrm{kg} / \mathrm{m} 2)$ Due to body mass index (BMI) has an adverse effect on reproduction, a higher incidence of menstrual dysfunction and anovulation was found in overweight women, possibly because of the alteration in secretion of gonadotropin releasing hormone, sex hormone binding globulin, adrenal and ovarian androgen, and luteinizing hormone and also because of altered insulin resistance ${ }^{(10)}$. Being a cheap, safe, and reasonably effective drug; Clomiphene citrate (CC) has withstood the test of time despite its all drawbacks. Therefore, the use of other protocols of ovulation induction in PCOS, including letrozole, has been limited to cases of $\mathrm{CC}$ resistance, failure, or intolerance ${ }^{(11)}$. Effectiveness and cost-effectiveness of other protocols were also compared to CC. This approach is rational when costly, hazardous, or invasive interventions like gonadotropin stimulation or laparoscopic ovarian drilling (LOD) are considered (1). Letrozole, however, is similarly safe, relatively inexpensive, and reasonably effective drug. The drug, therefore, deserves a fair comparison with CC. Letrozole was the first aromatase inhibitor to be used for this indication. Studies on letrozole were mostly conducted on clomiphene resistant cases, and 
because of its short history in this respect, concepts like letrozole resistance ${ }^{(12)}$. The largest study comparing Clomiphene citrate to Letrozole was by Badawy et al. ${ }^{(13)}$ demonstrated that the mean of E2 was significantly elevated in women under Clomid comparing with women who received Letrozole. Ibrahim et al., ${ }^{(14)}$ also demonstrated that serum estradiol was significantly greater in the CC group. In an agreement with this study finding, Wu et al., ${ }^{(11)}$ showed no significant difference in pregnancy rates and ovulation was found between the two drugs. Ibrahim et al., ${ }^{(14)}$ also demonstrated that the clinical pregnancy rate was significantly higher in letrozole group ( 23.07 vs $10.68 \%, P<0.001)$. There was significant increase in endometrial receptivity in letrozole group as assessed by endometrial thickness and Doppler flow indices of uterine and subendometrial vessels statistically. No harmful side effects were reported in either group. Moreover, Majeed ${ }^{(15)}$ proposed that, Letrozole appears to be a suitable ovulation inducing agent in PCOS women with CC failure and a significant higher pregnancy rate was observed in letrozole co treatment with gonadotropins. The finding of current study was also a good agreement with previous reports which conclude that letrozole has a better ovulation and pregnancy rate in patients with $\operatorname{PCOS}^{(16,17)}$. Letrozole administration in early follicular phase blocks estrogen syntheses, and causes temporary accumulation of androgens in ovarian follicles, the accumulation of androgens may increase the sensitivity of the growing follicles to FSH by increasing the expression of FSH receptors ${ }^{(13)}$. In addition, Dehbashi et al., ${ }^{(4)}$ showed that no significant increase in pregnancy rate was observed in the letrozole group. A non-significant increase in pregnancy rate was observed in patients receiving the letrozole treatment ${ }^{(10)}$. Moreover, Sammour et al., ${ }^{(18)}$ concluded that the pregnancy rate per cycle was $11.5 \%$ in the letrozole group and $8.9 \%$ in the clomiphene group (similar pregnancy rate)m they studied total 238 cycles of IUI and superovulation in women with idiopathic infertility. Patients were randomized to receive 7.5 $\mathrm{mg}$ of letrozole or $100 \mathrm{mg}$ of clomiphene daily. There was no significant difference between the total number of developing follicles in both groups the letrozole (5.7 \pm 3.7$)$ and in the clomiphene groups (4.8 \pm 2.3$)$.

\section{Conclusions}

It was concluded that, the number of follicles, Hyaluronic acid concentration, and the mean of Estradiole2 level at the day of trigger elevated significantly in women received letrozole than clomiphene as a treatment for non ovulatory infertility in women, and the pregnancy rate also is higher in letrozole plus gonadotropin group.

Financial Disclosure: There is no financial disclosure.

Conflict of Interest: None to declare.

Ethical Clearance: All experimental protocols were approved under the Al-Nahrain University and all experiments were carried out in accordance with approved guidelines.

\section{References}

1. Rao KA. The infertility manual. Jaypee Brothers, Medical Publishers Pvt. Limited. 2018.

2. Campbell S. Ultrasound Evaluation in Female Infertility: Part 1, the Ovary and the Follicle. Obstetrics and Gynecology Clinics. 2019;46(4):68396.

3. Chun S, Seo JE, Rim YJ, Joo JH, Lee YC, Koo YH. Efficacy of hyaluronan-rich transfer medium on implantation and pregnancy rates in fresh and frozen-thawed blastocyst transfers in Korean women with previous implantation failure. Obstetrics \& gynecology science. 2016;59(3): 201-7.

4. Dehbashi S, Dehbashi S, KAZEROUNI T, Robati M, Alborzi S, Parsanezhad ME, SHADMAND A. Comparison of the effects of letrozole and clomiphene citrate on ovulation and pregnancy rate in patients with polycystic ovary syndrome.

5. Eccles A. Obstetrics and gynaecology in Tudor and Stuart England. Routledge; 2018.

6. Elsedeek MS, Elmaghraby HA. Predictors and characteristics of letrozole induced ovulation in comparison with clomiphene induced ovulation in anovulatory PCOS women. Middle East Fertility Society Journal. 2011;16(2):125-30.

7. Ahmeid MS. Correlation between follicular fluid leptin and the pregnancy rate in women who underwent ICSI. Tikrit Med J. 2017;22:248-53.

8. Hameed BL, Ahmeid MS. Serum follistatin and its role in intracytoplasmic sperm injection outcomes. Medical Journal of Babylon. 2019;16(4):302.

9. Al-Hussaini TK, Shaaban OM. Aspiration of endometrial cavity fluid at the time of egg collection. Middle East Fertility Society Journal. 
2018;23(4):354-6.

10. Kamath MS, George K. Letrozole or clomiphene citrate as first line for anovulatory infertility: a debate. Reproductive Biology and Endocrinology. 2011; 9(1): 86.

11. Wu HH, Wang NM, Cheng ML, Hsieh JN. A randomized comparison of ovulation induction and hormone profile between the aromatase inhibitor anastrozole and clomiphene citrate in women with infertility. Gynecological endocrinology. 2007;23(2):76-81.

12. Wallace KL, Johnson V, Sopelak V, Hines R. Clomiphene citrate versus letrozole: molecular analysis of the endometrium in women with polycystic ovary syndrome. Fertility and sterility. 2011;96(4):1051-6.

13. Badawy A, Aal IA, Abulatta M. Clomiphene citrate or letrozole for ovulation induction in women with polycystic ovarian syndrome: a prospective randomized trial. Fertility and sterility. 2009;92(3):849-52.

14. Ibrahim MI, Moustafa RA, Abdel-Azeem AA. Letrozole versus clomiphene citrate for superovulation in Egyptian women with unexplained infertility: a randomized controlled trial. Archives of gynecology and obstetrics. 2012; 286(6): 1581-7.
15. Majeed BM. Comparison of letrozole with gonadotropins and letrozole_gonadotropin combination for ovulation induction in PCOS women after clomiphene citrate failure. Tikret Journal of Pharmaceutical Sciences. 2013;9(1):5460.

16. Begum MR, Ferdous J, Begum A, Quadir E. Comparison of efficacy of aromatase inhibitor and clomiphene citrate in induction of ovulation in polycystic ovarian syndrome. Fertility and sterility. 2009 Sep 1;92(3):853-7.

17. Abediasl Z, Rashidi BH, Shariat $M$, Amirchaghmaghi E. Comparison of the efficacy of the aromatase inhibitor letrozole and clomiphen citrate gonadotropins in controlled ovarian hyperstimulation: a prospective, simply randomized, clinical trial. Journal of assisted reproduction and genetics. 2008;25(5):187.

18. Sammour A, Biljan MM, Tan SL, Tulandi T. Prospective randomized trial comparing the effects of letrazole (LE) and clomiphene citrate (CC) on follicular development, endometrial thickness and pregnancy rate in patients undergoing superovulation prior to intrauterine insemination (IUI). Fertility and Sterility. 2001;3(76):S110. 